\title{
Evaluation of Antimicrobial Efficacy of Triantibiotic Paste, Mixture of Calcium Hydroxide and Omeprazole and Carnosic Acid as Intracanal Medicament against $E$. faecalis
}

\author{
${ }^{1}$ Amruta R Chougule, ${ }^{2}$ Neeta Shetty, ${ }^{3}$ Vishwas Saralaya, ${ }^{4}$ Kundabala M
}

\begin{abstract}
Introduction: Bacteria plays a principal role in the pathogenesis and progression of pulpal and periapical diseases. The chronic resistant bacterial existence in the root canals has a greater influence on the endodontic treatment outcome by the persistence of periapical tissues. Higher proportions of enterococci, ranging from 29 to $77 \%$ are found in filled root canals with the persistent periapical disease. Placement of an intracanal medicament can reduce the bacterial load.
\end{abstract}

Materials and methods: Extracted and decoronated, 72 nos. single-rooted human teeth prepared to maintain the root length of $18 \mathrm{~mm}$ were selected for the study. After instrumentation, E. faecalis suspension was inoculated in each of the root canal and teeth were incubated at $37^{\circ} \mathrm{C}$ for 72 hours within the orbital incubator. Root canal samples were randomly divided into four groups. After placement of various medicaments (namely saline, triantibiotic paste, mixture of calcium hydroxide $\left[\mathrm{Ca}(\mathrm{OH})_{2}\right]$ and omeprazole and carnosic acid) inside the canal, teeth were divided into three subgroups of five samples and incubated at $37^{\circ} \mathrm{C}$ under humid conditions for the time period of 24 hours, 48 hours and 7 days within Orbital incubator. Viable cell count assay was used to see the effect of these antimicrobials on $E$. faecalis biofilm.

Results: Results were statistically evaluated using KruskalWallis one-way analysis of variance tests. A p-value $<0.05$ was considered significant

Conclusion: Carnosic acid showed better antimicrobial properties compared to TAP, calcium hydroxide and omeprazole over the experimental period of time.

Clinical significance: A preliminary study using carnosic acid which is a plant derivative as an intracanal medicament.

Keywords: Biofilm, Calcium hydroxide, Carnosic acid, Enterococcus faecalis, Intracanal medicament, Omeprazole, Triantibiotic paste.

How to cite this article: Chougule AR, Shetty N, Saralaya V, Kundabala M. Evaluation of Antimicrobial Efficacy of Triantibiotic Paste, Mixture of Calcium Hydroxide and Omeprazole and

\footnotetext{
1,2,4 Department of Conservative Dentistry and Endodontics, Manipal Academy of Higher Education, Mangaluru, Karnataka, India

${ }^{3}$ Department of Microbiology, Kasturba Medical College, Mangaluru, Karnataka, India
}

Corresponding Author: Neeta Shetty, Department of Conservative Dentistry and Endodontics, Manipal College of Dental Sciences, Mangaluru, Karnataka, India, Phone: +91 9945644747, e-mail: neeta.shetty@manipal.edu
Carnosic Acid as Intracanal Medicament against E. faecalis. World J Dent 2018;9(5):401-405.

\section{Source of support: Nil}

Conflict of interest: None

\section{INTRODUCTION}

An infected root canal system serves as a unique locale for the selective species of the microbial flora of endodontic origin. ${ }^{1,2}$ Complexities of root canal systems, virulence of endodontic microbes, the action of dentinal fluid in decreasing the antiseptic activity of medicaments, relative diffusion of antimicrobials, bacteria in the biofilms are some of the factors that hamper the total eradication of microbes by intracanal medication. ${ }^{3}$ Majority of studies have depicted that sustained endodontic infections are often caused by Enterococcus faecalis. ${ }^{1,4-6}$ Virulence factors of E. faecalis which play a key role in the bacterium's pathogenesis are hemolysin, gelatinase, and enterococcal aggregation substance (EAS). Medications used during root canal therapy may not act on E. faecalis because of their capacity to withstand higher $\mathrm{pH}$ range up to 11.5 or lower. ${ }^{4,7}$ E. faecalis surviving in biofilms are 1000 times more resistant to antimicrobials used during therapy, phagocytic process, antibodies produced, than nonbiofilm producing bacteria. ${ }^{8}$

Since $1920, \mathrm{Ca}(\mathrm{OH})_{2}$ has been used in dentistry for its antimicrobial action, which is exerted predominantly by direct contact with bacteria through $\mathrm{pH}$ effects. ${ }^{9} \mathrm{Ca}(\mathrm{OH})_{2}$ has limited action on $E$. faecalis, since it thrives in an alkaline medium and maintains cytoplasmic homeostasis, using a prevailing functional proton pump in their cell membrane. ${ }^{6,7}$ Wagner et al. to increase the effectiveness of $\mathrm{Ca}(\mathrm{OH})_{2}$ suggested omeprazole as a proton pump inhibitor. ${ }^{10}$ As root canal infections are polymicrobial in nature, Hoshino et al. used a combination of antibiotics. ${ }^{11}$ Triple antibiotic paste (TAP) which consists of Metronidazole, minocycline, and ciprofloxacin is the most widely used medicament to disinfect necrotic teeth, to promote healing of periapical tissue and also during the endodontic regenerative procedure. ${ }^{12,13}$

Rosmarinus officinalis L. (Lamiaceae) is an edible evergreen shrub native to the Mediterranean area. Its main ingredients are rosmarinic acid, carnosic acid, carnosol, 
ursolic acid, oleanolic acid, genkwanin, apigenin, and luteolin. ${ }^{14}$ A bioassay-guided fractionation of the leaf extract of $R$. officinalis led to the discovery of carnosic acid and carnosol as the major compounds displaying the highest activity against oral pathogens as Streptococcus mutans, S. salivarius, S. sobrinus, S. mitis, S. sanguinis, and Enterococcus faecalis. ${ }^{14}$ It also exhibits anti-in ammatory and anticarcinogenic action. ${ }^{15,16}$ Wang et al. have shown that carnosic acid has a relatively low oral toxicity profile and their oral median lethal dose (LD50) was $7100 \mathrm{mg} / \mathrm{kg}$ body weight for mice. ${ }^{17}$ But there is a paucity of literature on carnosic acid using it for intracanal medication.

Hence the purpose of this study to comparatively evaluate the antimicrobial efficacy of triantibiotic paste, a mixture of $\mathrm{Ca}(\mathrm{OH})_{2}$ and omeprazole, and carnosic acid (R. officinalis leaf extract) on E. faecalis biofilm as an intracanal medicament.

\section{MATERIALS AND METHODS}

\section{Methodology}

The study was conducted after obtaining Institutional ethical committee (Protocol no: 13143) approval.

\section{Selection and Preparation of the Samples}

Seventy-two extracted single-rooted human teeth with class I root anatomy were selected for the study. Teeth were decoronated maintaining the root length of $18 \mathrm{~mm}$. After ensuring apical patency with\#15 K-file (Dentsply Maillefer, Ballaigues, Switzerland), root canals were enlarged up to\#20 K-file (Dentsply Maillefer, Ballaigues, Switzerland). Instrumentation of the root canal system is done using Protaper rotary nickel-titanium system (Dentsply Maillefer, Ballaigues, Switzerland) up to finishing file $\mathrm{F} 3$ using $2.5 \% \mathrm{NaOCl}$ for irrigation. Finally, all the teeth were irrigated with $17 \%$ EDTA followed by $2.5 \%$ $\mathrm{NaOCl}$ and sterile water to eliminate the smear layer. The apical foramens of all the roots were sealed with cyanoacrylate, and they were fixed in the center of screw-cap plastic vials and autoclaved twice. After autoclaving, one sample tooth (S1) was taken and evaluated under SEM to show sterile canal. Negative control (group V) was sterile tooth samples without $E$. faecalis biofilm $(\mathrm{n}=5)$.

\section{Biofilm Development}

A clinical isolate of E. faecalis obtained from the Microbiology Laboratory (Department of Microbiology, $\mathrm{KMC}$, Mangaluru) was used for the inoculation. The experimental suspension of E. faecalis ATCC19433 was prepared in BHI broth, which had its optical density adjusted to approximately $10^{8}$ colony forming units (CFUs) $\mathrm{m}^{\mathrm{L}-1}$ by comparing its turbidity to a McFarland 0.5
$\mathrm{BaSO}_{4}$ standard solution. Each root canal was inoculated with $10 \mu \mathrm{l}$ of the E. faecalis suspension using sterile $1 \mathrm{ml}$ tuberculin syringes. The blocks were then placed inside stainless steel boxes and incubated at $37^{\circ} \mathrm{C}$ for $72 \mathrm{~h}$ within Orbital Incubator (Sanyo).

\section{Verification of Biofilm Development}

One tooth infected by E. faecalis (approximately $10^{8} \mathrm{CFU} /$ $\mathrm{mL}$ ) (S2) was longitudinally sectioned using chisel and hammer into two halves. Then the sample was dehydrated, mounted on stubs, gold sputtered, and evaluated under scanning electron microscopy (SEM) operated at $15 \mathrm{~kW}$. using $500 \mathrm{X}$ magnification, pre- intracanal medicament placement biofilm formation was confirmed.

\section{Preparation of the Intracanal Medicament}

The intracanal dressing was prepared according to experimental groups.

\section{Preparation of Triantibiotic Paste}

Ciprofloxacin (Ciplox $500 \mathrm{mg}$ tablet, Cipla India), metronidazole (Metrogyl $400 \mathrm{mg}$ tablet, JB Chemicals and Pharmaceuticals Ltd) and minocycline (Minoz, 100mg tablet, Ranbaxy India.) were weighed separately in a digital weighing machine to obtain a 1:1:1 proportion for mixing together to obtain a triple antibiotic powder. ${ }^{1}$

\section{Preparation of Calcium Hydroxide and Omeprazole}

Omeprazole powder (Capsule Omez DR. Reddy's India) was prepared by grinding the contents to a fine powder using sterile mortar and pestle. The omeprazole powder and $\mathrm{Ca}(\mathrm{OH})_{2}$ were weighed to obtain a 1:1 proportion for mixing together. ${ }^{2}$

\section{Preparation of Carnosic Acid}

Carnosic acid is available as a powder which was dispensed on the paper pad just before its use.

\section{Preparation of Paste}

The pastes were prepared just before placement of medicament by mixing the powder with propylene glycol vehicle.

\section{Application of the Medicament}

The lentulo spiral was used for placement of the paste inside the infected canals. After placement of various medicaments, the groups were randomly again divided into three subgroups of five samples each and incubated at $37^{\circ} \mathrm{C}$ under humid conditions for the different experimental time period of 24 hours, 48 hours and 7 days 
within Orbital Incubator. Group I consisted of $0.85 \%$ saline, group II, TAP group III mixture of $\mathrm{Ca}(\mathrm{OH})_{2}$ and omeprazole and group IV carnosic acid.

\section{Bacterial Sampling}

After incubation for 24 hours at $37^{\circ} \mathrm{C}$, samples ( $\mathrm{n}=5$ from each group) were uncovered in an aseptic environment. The colony counts were performed for these samples. Similarly, after 48 hours ( $\mathrm{n}=5$ from each group) and the 7th day ( $\mathrm{n}=5$ from each group) of incubation, the colony counts were performed. Samples from each group were irrigated with $20 \mathrm{~mL}$ of the sterile saline solution to remove intracanal medicament. The \#15 K-file is used to circumferentially file the canal for 10 seconds. Following this, three \#25 sterile absorbent paper points were successively inserted into the root canals and after 1 minute, were transported to a test tube containing $1.0 \mathrm{~mL}$ of saline. All samples were vortexed for twenty seconds and 10-fold dilutions were prepared in saline.

\section{Microbiological Monitoring}

One hundred- $\mu \mathrm{l}$ aliquot made from collected samples were spread onto brain heart infusion agar (BHIA; Difco, Detroit, MI) in triplicate. Incubating at $37^{\circ} \mathrm{C}$ for 48 hours, cultures were examined, for estimation of the number of colony-forming units (CFU)/mL. Gram staining and catalase testing were used to confirm Mono-infection by E. faecalis.

\section{RESULTS}

Manual counting of colony forming units (CFU) was performed after 72 hours of incubation of E. faecalis into the canals before placement of intracanal medicament in each group. The counting was repeated after placement of medicament in a similar manner for five samples in each group at a time period of 24 hours, 48 hours and 7 days. Data were normalized by $\log 10$ transformation of each CFU/mL value and analyzed by Kruskal-Wallis one-way analysis of variance test to determine statistical significance and a p-value $<0.05$ was considered significant. Statistical analysis was performed with the statistical software SPSS version15.0 (SPSS for Windows; SPSS Inc, Chicago, IL). The scanning electron microscope analysis showed root canal dentin surface with or without biofilm. There was statistically $(\mathrm{p}<0.001)$ reduction in no of CFU/mL in group II, III and IV when compared with group I. There is a statistically significant reduction in the no of CFU/mL in group II, and IV when compared to group III (Graph 1 and Table 1).

\section{DISCUSSION}

Results have shown that E. faecalis biofilm was susceptible to all the three test materials used in the study. There was a significant reduction in CFU/mL in 24 hours, 48 hours and 7 days after placement of medicament in group II, III and IV when compared to CFU/mL in control group I. This difference was found to be statistically significant. This shows that all the three materials used in the study namely triantibiotic paste, $\mathrm{Ca}(\mathrm{OH})_{2}$ plus omeprazole and carnosic acid shows potent antimicrobial activity. In the present study TAP (group II) showed better results by successfully in eradicating $E$. faecalis as compared to group III $\left[\mathrm{Ca}(\mathrm{OH})_{2}\right.$ plus omeprazole] and showed

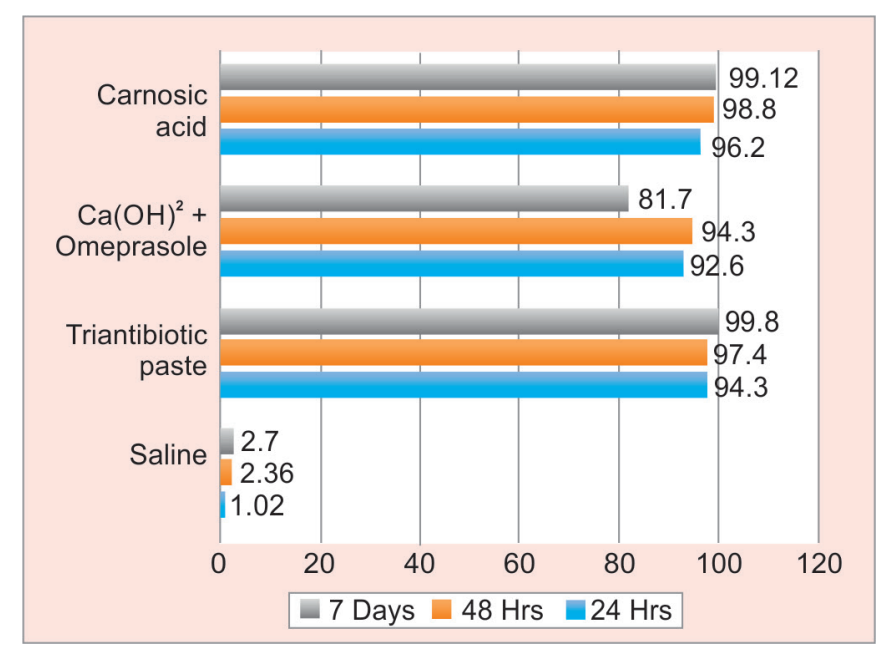

Graph 1: Percentage reduction in colony forming units (CFU)/ $\mathrm{mL}$ of Enterococcus faecalis within root canals after exposure to medicaments for varying periods of time

Table 1: Comparison of the effect of medicaments with the control group (Group I-Saline) on the count of Enterococcus faecalis ATCC 29212 within root canal preparations

\begin{tabular}{|c|c|c|c|c|c|}
\hline \multirow[b]{2}{*}{ Hours/Days of Incubation } & \multicolumn{5}{|c|}{ Mean Percentage ( $\pm S D$ ) reduction in Colony forming units $(C F U) / m L$} \\
\hline & Group I & (Saline) & $\begin{array}{l}\text { Group II * } \\
\text { (Triantibiotic paste) }\end{array}$ & $\begin{array}{l}\text { Group III* } \\
\left(\mathrm{Ca}(\mathrm{OH})_{2}+\right. \\
\text { Omeprazole) }\end{array}$ & $\begin{array}{l}\text { Group IV* } \\
\text { (Carnosic acid) }\end{array}$ \\
\hline $0 \mathrm{Hrs}(\mathrm{S} 0)$ & 100 & & - & - & - \\
\hline After 24 Hrs (S1) & $1.02 \pm 0.91$ & & $94.35 \pm 3.66$ & $92.61 \pm 4.8$ & $96.22 \pm 4.41$ \\
\hline After 48 Hrs (S2) & $2.36 \pm 1.3$ & & $97.40 \pm 2.11$ & $94.30 \pm 5.36$ & $98.85 \pm 2.88$ \\
\hline After 7 days (S3) & $2.70 \pm 1.9$ & & $99.83 \pm 1.41 \$$ & $81.71 \pm 6.23$ & $99.12 \pm 1.1 \$$ \\
\hline
\end{tabular}

*Statistically significant $(p<0.001)$ reduction in no of CFU/mL in Groups II, III and IV when compared with Group I; $\$$ statistically significant $(p<0.05)$ reduction in no of CFU/mL in groups II and IV when compared to Group III 
comparable results with group IV (carnosic acid). It has shown a continuous reduction in $\mathrm{CFU} / \mathrm{ml}$ count from 24 hours till 7 days. These findings are consistent with the study done by Madhubala et al. in which propolis and TAP have shown higher antimicrobial activity against E. faecalis as compared to calcium hydroxide. ${ }^{17}$ A study by Sabrah et al. has also shown that TAP had greater antimicrobial activity in comparison to $\mathrm{Ca}(\mathrm{OH})_{2}$ against E. faecalis and Porphyromonas gingivalis. ${ }^{18}$ Results obtained in the present study could be attributed to the synergistic action of antibiotics used in TAP. The TAP was shown to have complete inhibition of E. faecalis strain on BHI agar plates. ${ }^{19}$

Results have shown that the bactericidal effect of the combination of $\mathrm{Ca}(\mathrm{OH})_{2}$ plus omeprazole (group III) was initially high at 24 hours and 48 hours of the experimental period, but its antimicrobial efficacy significantly reduced at day 7 when compared with other groups (groups II and IV). Wagner et al. have shown the lack of effect of $\mathrm{Ca}(\mathrm{OH})_{2}$ plus omeprazole on total $\mathrm{CFU}$ counts at 15 and 28 days' time interval. ${ }^{13}$

According to the present study, group IV (carnosic acid) has shown a maximum reduction in colony count in 24 hours and 48 hours when compared to groups II and III. Carnosic acid (group IV) showed comparable results to TAP (group II). The reduction in CFU/mL was observed subsequently over 48 hours and 7 days. This shows that carnosic acid has higher antimicrobial activity against E. faecalis which increases continuously over a consecutive period of time. There was a statistically significant difference between groups III and IV at 7 days interval. The antimicrobial effect of group IV can be attributed to its efflux pump modulator effect by dissipation of the cell membrane potential of E. faecalis. ${ }^{20}$

There are no previous studies to show the effectiveness of carnosic acid as an intracanal medicament. But several studies have shown it to be effective against various oral pathogens including E. faecalis..$^{14,15,21,22}$ Mechanisms regarding antimicrobial activities of this phenolic diterpenes is still unknown. Speculations for its antimicrobial activity can be explained by two mechanisms, firstly the lipophilic structure of these compounds allows them to insert into the bacterial membrane, where their hydrogen bond donor group(s) could interact with membrane phosphorylated groups and secondly, the carnosic acid acts as a modulator of the ethidium bromide efflux which is responsible for membrane permeability. ${ }^{20,23}$

According to findings of the present study carnosic acid (group IV) was more efficacious than the combination of $\mathrm{Ca}(\mathrm{OH})_{2}$ plus omeprazole (group III) and its antimicrobial efficacy was comparable to TAP (group II) in eradicating E. faecalis biofilm. Although the TAP has shown good antimicrobial activity, it has several known disadvantages such as dentin staining, the concern of development of resistant bacterial strain. ${ }^{23}$ From the results of this study, it can be concluded that carnosic acid can be considered an effective and comparable substitute to TAP. But further extensive in vitro and in vivo studies are required for evaluation of its antimicrobial efficacy since this material has not been previously used in endodontics.

\section{CLINICAL SIGNIFICANCE}

Carnosic acid which is a plant derivative shows comparable antimicrobial efficacy to TAP as an intracanal medicament in the preliminary study.

\section{REFERENCES}

1. Peciuliene V, Balciuniene I, Eriksen HM HM. Isolation of Enterococcus faecalis in previously rootfilled canals in a Lithuanian population. J Endod. 2000;26:593-595.

2. Peciuliene V, Reynaud AH, Balciuniene IHM. Isolation of yeasts and enteric bacteria in root-filled teeth with chronic apical periodontitis. Int Endod J. 2001;34:429-434.

3. Soares JA, Roque de Carvalho MA, Cunha Santos SM, Mendonça RMC, Ribeiro-Sobrinho AP, Brito-Júnior M et al. Effectiveness of chemomechanical preparation with alternating use of sodium hypochlorite and EDTA in eliminating intracanal Enterococcus faecalis biofilm. J Endod. 2010 May;36(5):894-898.

4. Byström A, Claesson RSG. The antibacterial effect of camphorated paramonochlorophenol, camphorated phenol and calcium hydroxide in the treatment of infected root canals. Endod Dent Traumatol. 1985;1:170-175.

5. Pinheiro ET, Gomes BP, Ferraz CC, Sousa EL, Teixeira FB S-FF. Microorganisms from canals of root-filled teeth with periapical lesions. Int Endod J. 2003;36:1-11.

6. Gomes BP, Pinheiro ET, Jacinto RC, Zaia AA, Ferraz CC S-FF. Microbial analysis of canals of root-filled teeth with periapical lesions using polymerase chain reaction. J Endod. 2008;34(5):537-540.

7. Evans M, Davies JK, Sundqvist G FD. Mechanisms involved in the resistance of Enterococcus faecalis to calcium hydroxide. Int Endod J. 2002;35:221-228.

8. Distel JW, Hatton JF, Gillespie MJ. Biofilm Formation in Medicated Root Canals. J Endod. 2002;28(10):689-693.

9. Gomes BPFDA, Ferraz CCR, Vianna ME, Rosalen PL, Zaia AA, Teixeira FB, et al. In vitro antimicrobial activity of calcium hydroxide pastes and their vehicles against selected microorganisms. Braz Dent J 2002;13(3):155-161.

10. Wagner C, Barth VC, de Oliveira SD, Campos MM. Effectiveness of the proton pump inhibitor omeprazole associated with calcium hydroxide as intracanal medication: an in vivo study. J Endod 2011 Sep;37(9):1253-1257.

11. Hoshino E, Kurihara-Ando N, Sato I, Uematsu H, Sato M, Kota K IM. In-vitro antibacterial susceptibility of bacteria taken from infected root dentine to a mixture of ciprofloxacin, metronidazole and minocycline. Int Endod J. 1996;29(2): 125-130.

12. Bose R, Nummikoski P, Hargreaves K. A Retrospective Evaluation of Radiographic Outcomes in Immature Teeth 
With Necrotic Root Canal Systems Treated With Regenerative Endodontic Procedures. J Endod. 2009;35(10):1343-1349.

13. Taneja S, Kumari M, Parkash H. Nonsurgical healing of large periradicular lesions using a triple antibiotic paste: A case series. Contemp Clin Dent. 2010;1(1):31.

14. Bernardes WA, Lucarini R, Tozatti MG, Souza MGM, Andrade Silva ML, da Silva Filho AA, et al. Antimicrobial Activity of Rosmarinus officinalis against Oral Pathogens: Relevance of Carnosic Acid and Carnosol. Chem Biodivers. 2010 Jul 15;7(7): 1835-1840.

15. Barni M V, Carlini MJ, Cafferata EG, Puricelli L, Moreno S. Carnosic acid inhibits the proliferation and migration capacity of human colorectal cancer cells. Oncol Rep. 2012;27(4):1041-1048.

16. Mengoni ES, Vichera G, Rigano LA, Rodriguez-Puebla ML, Galliano SR, Cafferata EE, et al. Suppression of COX-2, IL-1 and TNF- expression and leukocyte infiltration in inflamed skin by bioactive compounds from Rosmarinus officinalis $\mathrm{L}$. Fitoterapia. 2011;Apr;82(3):414-421.

17. Wang QL, Li H, Li XX, Cui CY, Wang R, Yu NX, et al. Acute and 30-day oral toxicity studies of administered carnosic acid. Food Chem Toxicol. Elsevier Ltd; 2012;50(3650):4348-4355.
18. Sabrah AH a, Yassen GH, Gregory RL. Effectiveness of antibiotic medicaments against biofilm formation of Enterococcus faecalis and Porphyromonas gingivalis. J Endod. Elsevier Ltd; 2013 Nov;39(11):1385-1389.

19. Molander A, Reit C, Dahlén G, Kvist T. Microbiological status of root-filled teeth with apical periodontitis. Int Endod J. 1998;31(1):1-7.

20. Nair PN. Pathogenesis of apical periodontitis and the causes of endodontic failures. Critical Reviews in Oral Biology \& Medicine. 2004 Nov;15(6):348-381.

21. Iris C, Myriam E, Roxana M, María I. Antibacterial potential of non-volatile constituents of Rosmarinus officinalis against 37 clinical isolates of multidrug-resistant bacteria. Bol Latinoam Caribe Plant Med Aromat 2013;12(2):201-208.

22. Ojeda-Sana AM, Repetto V, Moreno S. Carnosic acid is an efflux pumps modulator by dissipation of the membrane potential in Enterococcus faecalis and Staphylococcus aureus. World J Microbiol Biotechnol. 2013 Jan [cited 2015 Apr 7];29(1):137-144.

23. Sedgley C, Nagel A, Dahlén G, Reit C, Molander A. Real-time quantitative polymerase chain reaction and culture analyses of Enterococcus faecalis in root canals. J Endod. 2006;32(3):173-177. 